\title{
DIMENSÕES DA CRISE DO SINDICALISMO BRASILEIRO
}

\author{
Adalberto Moreira Cardoso*
}

\begin{abstract}
O artigo inquire a propalada crise do sindicalismo brasileiro na última década. Analisa algumas dimensões centrais do ordenamento sindical do país (número de sindicatos existentes, filiação a centrais sindicais, taxa de filiação sindical, volume de greves, negociação coletiva e outros), e mostra que, apesar da queda acentuada nas taxas de filiação, a ação sindical tem se mostrado eficiente na negociação coletiva. A imagem da crise está associada ao ambiente político mais geral, no qual o projeto político da parcela hegemônica do movimento (a CUT e aliados) e seus partidos (o PT e aliados) estão, hoje, sob fogo cerrado das forças que se lhes opõem.
\end{abstract}

Palavras-chave: Sindicalismo. Crise econômica. Crise política. Negociação coletiva. Greves.

\section{INTRODUÇÃO}

Em 2013, Marco Aurélio Santana convidou a mim e outros colegas para compor uma mesa sobre sindicalismo, no $37^{\circ}$ Encontro Anual da Associação Nacional dos Programas de Pós-Graduação em Ciências Sociais (ANPOCS). A mesa tinha título provocador: "Para onde foram os sindicatos?". Provocador porque trazia uma mensagem não tão subliminar assim. Era como se os sindicatos brasileiros tivessem desaparecido da cena política e social do país.

A mensagem era paradoxal, porque os que estudam o sindicalismo no Brasil sabem, por exemplo, que o número de sindicatos não para de crescer, que as greves são em geral bem sucedidas, que a negociação coletiva tem conseguido manter o poder de compra dos salários e mesmo assegurar ganhos reais, dentre outros indicadores relevantes analisados mais tarde neste artigo. Além disso, no momento em

* Instituto de Estudos Sociais e Políticos (IESP) da Universidade Estadual do Rio de Janeiro.

Rua da Matriz, 82. Cep: 22260-100. Botafogo - Rio de Janeiro - Rio de Janeiro - Brasil. acardoso@iesp.uerj.br que escrevo (junho de 2015), um partido com origem no movimento sindical está no poder federal há mais de 12 anos, e, ao menos até antes da eclosão da crise política por aqui, em junho de 2013, os índices de aprovação governamental eram muito altos. Por que, então, o título da mesa?

No subtexto da convocatória inicial estava a ideia de que o sindicalismo no Brasil vivia uma crise. O país estava para ser sacudido pelos protestos de junho de 2013, que ocorreriam ao largo e, na verdade, contra as instituições tradicionais de representação de interesses, dos partidos aos sindicatos, aos movimentos sociais mais institucionalizados, e o sindicalismo pareceu não ter o que oferecer aos manifestantes, nem estratégias políticas de longo prazo nem bandeiras imediatas, que flamulariam nas mãos dos mais variados coletivos que foram às ruas naquele mês, boa parte delas contra, justamente, os sindicatos e os partidos políticos. ${ }^{1}$

Ao aceitar o convite para a mesa da ANPOCS, aceitei, também, suas premissas, ${ }^{1}$ Ver Maricato et al. (2013) e o posfácio do livro de Castels (2013). 
embora criticamente. Como todos os demais membros da mesa, tomei como evidente a crise do sindicalismo no país, e fui atrás de indicadores que a comprovassem. E me deparei com um cenário paradoxal. Enquanto o "espírito do tempo" teimava em martelar a crise, os dados disponíveis não permitiam conclusões peremptórias, alguns deles indo na direção contrária à percepção geral. Exposto o problema naquela reunião da ANPOCS, decidi escrutinar mais longamente o paradoxo. Este artigo é o resultado desse escrutínio.

Nas páginas que se seguem, argumento que a crise do sindicalismo é real, embora, talvez, não pelas razões apontadas pela literatura. Há aspectos da dinâmica propriamente sindical que não são atentadas pelos analistas, que denotam problemas de reprodução do poder sindical no médio prazo; há outros aspectos salientados por muitos estudiosos que também apontam na mesma direção; há dimensões aparentemente virtuosas da ação sindical que não são devidamente enfatizadas pelas análises; e há, por fim, o ambiente político mais geral, que afeta de muitas maneiras o modo como o movimento sindical se pensa, define suas estratégias e age. Nas páginas que se seguem, discuto as dimensões que considero mais relevantes da crise, tentando associar a dinâmica propria-

\& riados urbanos, profissionais liberais, autôno-

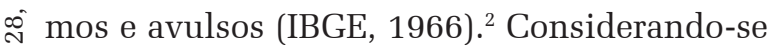
$>$

î 2 A sindicalização no campo era proibida no Brasil até 1960, e, a partir de 1961, houve um boom de criação de sindicatos rurais. Das 2,9 mil entidades rurais existentes స em 1991, 468 tinham sido fundadas entre 1960 e 1964. . Novo surto de sindicalização rural ocorreu entre 1970 e 1975, quando foram criados 1,1 mil sindicatos (Fonte: tabulação dos microdados da Pesquisa Sindical 1991, do IBGE, para este texto). Esses números são aproximados, diga-se desde logo, porque não se sabe quantos sindicatos deixaram de existir ou se fundiram com outros entre sua \& fundação e o ano do censo sindical de 1991. E os dados do os sindicatos de trabalhadores rurais, chegavase a 2.5 mil entidades. Em 1989, um ano após a promulgação de nova Constituição Federal, o mesmo IBGE computou mais de 6.600 entidades de trabalhadores do campo e da cidade, sendo que os sindicatos de assalariados urbanos eram pouco mais de 3.1 mil (IBGE, 1992). Os anos de 1988 e 1989, na verdade, assistiram ao maior número de criação de sindicatos da história até ali. Foram pouco mais de mil novas associações, 760 delas de assalariados urbanos. O efeito da nova Constituição de 1988, que liberou o sindicalismo do jugo do Ministério do Trabalho, foi imediato, como se vê. Mas os números não pararam de crescer.

Em 2001, novo censo sindical do IBGE encontrou 7,7 mil sindicatos de trabalhadores rurais e urbanos, 1,9 mil dos quais fundados entre 1991 e 2000, um quarto deles criados por servidores públicos, que não podiam se sindicalizar antes de $1988 .{ }^{3}$ Por fim, na aferição da representatividade das centrais sindicais brasileiras feita em 2015, com base nas informações de 2014, o Ministério do Trabalho e Emprego registrou a existência de 10.813 sindicatos de trabalhadores. Logo, foram criadas mais de 3 mil novas entidades em 13 anos.

Esses números poderiam sugerir pujança do movimento sindical brasileiro, já que mais sindicatos significariam, em tese, inclusão de mais trabalhadores às bases representadas, maior cobertura da negociação coletiva, maior penetração no território nacional etc. Mas não parece ser esse o caso. O ritmo intenso de criação de sindicatos depois de 1988 parece ter significado, de fato, maior fragmentação da representação sindical e, ao que tudo indica, perda de capacidade de atração de adeptos. Isso porque os sindicatos existentes em 2001 declararam filiar 19 milhões de pessoas ao censo do IBGE, enquanto em 2014 o número declarado

inquérito sindical sobre o período publicados pelo IBGE em seus Anuários Estatísticos não distinguem sindicatos urbanos de rurais.

${ }^{3}$ Dados do Censo Sindical de 2001 estão disponíveis em http://www.ibge.gov.br/home/estatistica/populacao/condicaodevida/sindical/default_result_completos.shtm. 
de filiados ao Ministério do Trabalho e Emprego foi de pouco mais de 8 milhões. ${ }^{4}$

Além da fragmentação das bases sindicais e da redução dos efetivos sindicais, as estatísticas de greves publicadas pelo DIEESE haviam alimentado, nos anos 1990 e início do novo milênio, várias análises sobre o declínio do sindicalismo no Brasil, em consonância com o que estava ocorrendo em todo o mundo, e, de um modo geral, a medida do declínio (para alguns, inexorável, como no caso exemplar de Rodrigues, 1999) era o que Noronha (2009) denominaria de ciclo excepcional de greves dos anos 1980, período de transição política também excepcional, no qual o sindicalismo brasileiro estava em processo de reconstrução e de delimitação de seus espaços de atuação na democracia que surgia. ${ }^{5}$ Para a maioria dos analistas posteriores ${ }^{6}$ as estatísticas existentes continuavam apontando que as greves estavam num patamar muito inferior ao seu pico histórico, com o quê a imagem da crise permaneceu. Aos dados estatísticos, os debates na imprensa e nos fora acadêmicos agregaram outros elementos críticos, relacionados tanto com a eficácia da ação sindical propriamente dita, isto é, de representação dos trabalhadores junto aos patrões, quanto com os aspectos expressivos e identitários do movimento, responsável, por exemplo, pela construção de visões de mundo alternativas ou transformadoras.

A se confiar nesses dados e análises, estaríamos, de fato, diante de uma crise do sindicalismo. Até que ponto esse diagnóstico se sustenta nos fatos? Se for esse o caso, quais as dimensões da crise? Há um futuro para o sindicalismo brasileiro?

${ }^{4}$ Ao preencher o formulário de registro no Cadastro Nacional de Entidades Sindicais do Ministério do Trabalho e Emprego os sindicatos precisam informar o número de trabalhadores na base, o número de filiados e o número de filiados quites com a instituição.

${ }^{5}$ Escrevi um livro extenso sobre a crise sindical dos anos 1990 (Cardoso, 2003).

${ }_{6}^{6}$ As principais exceções são Noronha (2009) e Boito Jr. e Marcelino (2010). Noronha argumenta que o período de 1998 a 2007 se caracterizou pela normalização das greves no país, que, depois do grande ciclo de 1978-1997, haviam retornado a um nível equivalente à média mundial. Boito e Marcelino falam em retomada do ímpeto grevista no país.

\section{RETRATOS DA “CRISE”}

\section{Filiação sindical}

A ação sindical pode ser mensurada de várias maneiras. Um dos indicadores mais utilizados internacionalmente é a taxa de filiação sindical, por permitir comparações entre países (Checchi e Visser, 2005). No Brasil, a fonte mais confiável para o escrutínio da filiação ainda é a Pesquisa Nacional por Amostra de Domicílios (PNAD), que, até 2013, perguntou aos moradores ocupados dos domicílios se eram filiados a um sindicato. ${ }^{7}$ Como se pode ler no Gráfico, em 2001, tomando-se apenas a população assalariada adulta (pessoas de 18 anos ou mais, incluindo servidores públicos, domésticos e assalariados sem carteira, além dos assalariados com carteira, do campo e da cidade), 19,3\% eram filiados a sindicatos. Em 2006, a taxa tinha subido a $21 \%$, e vem caindo desde então, tendo atingido 16,6\% em 2013. Trata-se da menor taxa registrada pelo IBGE na série histórica iniciada em 1988 (o Gráfico 1 mostra apenas o período 2001-2013).

A taxa de 16,6\% de 2013 equivalia a perto de 11 milhões de assalariados. Se considerarmos a população ocupada como um todo (inclusive empregadores), o número subia a 15 milhões de trabalhadores. A taxa de filiação da população ocupada foi de $16 \%$ em 2013 , depois de ter atingido o pico de 19,5\% em 2006. Por esses dados, em termos absolutos o número de filiados no Brasil ainda era muito alto, apesar da queda inconteste na taxa de adesão (ou densidade sindical, como empregado na literatura internacional). É verdade, como sugere Rodrigues (2013), que a queda da densidade na população ocupada total teria sido maior se não tivesse sido contra arrestada pelo crescimento da sindicalização no campo, sobretudo

${ }^{7}$ Em 2014, o IBGE suspendeu a PNAD anual, substituindo-a pela PNAD Contínua, realizada trimestralmente e com questionário bem mais simples. Dentre as muitas questões excluídas está a filiação a sindicato. Com isso, os analistas do mundo do trabalho perderam uma importante fonte de informação sobre a presença sindical na vida dos trabalhadores. 
(acrescento eu) entre os trabalhadores rurais por conta própria e não remunerados. A taxa de filiação dos ocupados rurais foi de $25 \%$ em 2013, segundo a mesma fonte, totalizando 3.5 milhões de pessoas, ou quase um quarto do total de filiados no Brasil.

Gráfico 1 - Taxa de filiação sindical da população ocupada adulta (18 anos ou mais) - Brasil, 2001-2013

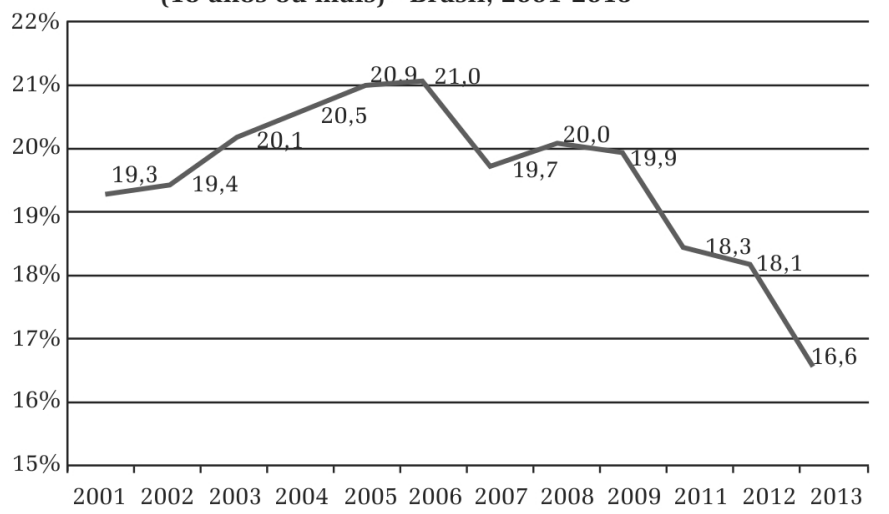

Fonte: Microdados da PNAD, vários anos.

As taxas de filiação retratam importante movimento de esvaziamento do sindicalismo urbano, com crescimento da filiação rural. Essa queda recente coincide com o crescimento estrondoso do número de empregos formais de má qualidade (Pochman, 2012), e, também, com o aumento nas taxas de rotatividade (processos que levam, em geral, à piora nos indicadores sindicais, tendo em vista a substitui으 ção de trabalhadores mais velhos por jovens ¿ entrantes no mercado de trabalho), e reflete, Ф் nesse sentido, mudanças na dinâmica do mercado de trabalho. Mas deve servir de alerta a tendência de queda na adesão aos sindicatos iniciada em 2006 e até aqui não estancada. Ainda que, como já mostrei em outros lugares (Cardoso, 2003 e 2013), a filiação não seja indicador adequado de pujança do sindicalismo no Brasil, a queda acentuada nas taxas (e de 2012 para 2013 houve queda também no montante absoluto) indica menor proximidade dos trabalhadores em relação às instituições que os representam compulsoriamente. Não se deve esquecer que apenas os filiados votam nas eleições sindicais. Com isso, a queda na filiação pode significar, também, maior oligarquização da representação sindical, tema que será retomado mais adiante e que considero aspecto central da crise atual.

Fonte adicional para o estudo da filiação sindical, agora que a PNAD não mais perguntará sobre isso, é o Cadastro Nacional de Entidades Sindicais (CNES), do Ministério do Trabalho e Emprego (MTE). O registro dos sindicatos no CNES é, por lei, voluntário. Contudo, tornou-se compulsório, na prática, para os sindicatos que pretendem acesso ao imposto sindical, já que decisão do Tribunal Superior do Trabalho (TST) de 2002 atribuiu ao Ministério a tarefa de "zelar pela unicidade sindical", prevista na Constituição Federal de 1988 (Cardoso e Lage, 2007). Essa decisão ocorreu contra o espírito da Constituição, que prevê liberdade sindical, e teve um motivo pragmático: ao longo de toda a década de 1990, havia cabido à Justiça do Trabalho decidir conflitos de jurisdição entre sindicatos em disputa por parcelas da mesma base territorial. Os conflitos foram inúmeros (e continuam), e decorreram da convivência contraditória, na própria Constituição, entre a regra da liberdade sindical e a que manteve o imposto sindical e a unicidade (um único sindicato para uma mesma categoria numa mesma base territorial).

Vale notar que o próprio MTE já havia tentado normatizar o registro sindical em 2000, através da Portaria 343, de 4 de maio. ${ }^{8}$ Foi uma maneira de disciplinar um processo que, até ali, estava a cargo do próprio movimento sindical. A Confederação Nacional do Comércio, por exemplo, havia constituído regras para registro dos sindicatos filiados a ela, ainda em 1991, através de sua Comissão de Enquadramento e Registro Sindical. ${ }^{9}$ Mas nem o $8 \quad$ Disponível em http://portal.mte.gov.br/data/files/
FF8080812BE914E6012BF9693ECD1E80/p_20000504_343.
pdf (acessado em maio de 2015).
9 Ver http://www.cnc.org.br/central-do-conhecimento/li-
vros/enquadramento-sindical-no-sicomercio (acessado em
maio de 2015). 
MTE nem as confederações haviam conseguido pacificar os conflitos de jurisdição.

De fato, até a portaria ministerial de 2000, para constituir um sindicato bastava às lideranças registrá-lo num cartório. Como, porém, o sindicato assim constituído pleiteava acesso ao imposto, caso já houvesse outro sindicato na mesma base territorial, isso gerava um conflito de jurisdição, que, invariavelmente, chegava às barras dos tribunais do trabalho. Foram inúmeros os sindicatos que tiveram suas bases fragmentadas dessa maneira, com categorias como a dos metalúrgicos sendo divididas em dezenas ou mesmo centenas de profissões (como serralheiros, montadores, mecânicos etc.) por lideranças sindicais interessadas no imposto sindical. A fragmentação ocorreu também na cúpula sindical, com a criação de novas federações e confederações, que também geraram conflitos judiciais.

Com a decisão de 2002, o TST devolveu definitivamente ao MTE a prerrogativa perdida em 1988, subordinando o reconhecimento de novas entidades ao seu poder discricionário. Para qualificar-se a uma decisão do Ministério que lhe garantirá acesso ao imposto, pois o sindicato deve requerer seu registro (ou reconhecimento). E, para isso, o Ministério ressuscitou instrumentos que o movimento sindical julgava sepultos para sempre, como a Comissão de Enquadramento Sindical, responsável por decidir se tal sindicato, que pleiteia existência, tem correspondência com uma atividade econômica existente no também ressurreto "Quadro de Atividades Econômicas e Profissões”, que, por décadas, havia orientado o controle ministerial sobre a criação de entidades sindicais. Ou seja, o artigo 581 da CLT, que regula o enquadramento, mas que estava em contradição com a Constituição, voltou, com todos os seus instrumentos, a ordenar o processo de criação de sindicatos.

Legislação de 2008 conferiu, ainda, mais poder ao MTE, ao garantir acesso das centrais sindicais a uma fatia (10\%) do mesmo imposto sindical, repartido entre elas segundo o núme- ro de trabalhadores filiados, número declarado pelos próprios sindicatos (Lei No 11.648, de 31 de março de 2008). Todos os anos o Ministro do Trabalho emite uma portaria sobre a aferição da representatividade das centrais sindicais, baseado nas informações fornecidas no ano anterior, e é com base nessa portaria que os recursos do imposto são rateados. ${ }^{10}$ Isso estimulou o movimento de registro das entidades sindicais no mesmo sistema do MTE, no qual informam, também, a qual central se filiam e o número de trabalhadores sindicalizados. A perda de autonomia sindical, ${ }^{11}$ então, teve uma contrapartida inesperada: constituiu-se um cadastro nacional de entidades sindicais, importante base de informação sobre a vida sindical antes inexistente.

Segundo o CNES, como já se disse, havia no Brasil, em 2014, perto de 11 mil sindicatos de trabalhadores com registro ativo e pouco mais de cinco mil sindicatos de empregadores. ${ }^{12}$ Havia, também, quatro mil entidades de trabalhadores com registros ainda por serem validados pelo MTE. Não consegui obter informação desagregada para 2014, apenas para 2013, ${ }^{13}$ e são esses os dados apresentados a seguir.

De saída, chama a atenção a discrepância entre os dados do CNES e da PNAD. Os 8.1

10 Ver http://www.diap.org.br/index.php?option=com-
content\&view=article\&id=25069:em-nova-afericao-das-
centrais-sindicais-cut-lidera-com-31-73\&catid=59\&Ite-
mid=392 para o despacho ministerial de 2015.
11 Para que se tenha a dimensão dessa perda de autono-
mia, portaria do MTE de janeiro de 2014 regulamenta a
concessão do código sindical, que permite ao sindicato
acesso aos recursos do imposto via Caixa Econômica Fe-
deral. Nela são detalhadas as obrigações dos sindicatos em
relação ao registro no CNES, e faz-se constante remissão
ao art. 588 da CLT, que, no seu segundo parágrafo, reza
que "A Caixa Econômica Federal remeterá, mensalmente,
a cada entidade sindical, um extrato da respectiva conta
corrente, e, quando solicitado, aos órgãos do Ministério do
Trabalho". Ou seja, o MTE pode solicitar acesso à conta cor-
rente na qual os sindicatos recebem o imposto sindical. O fato
de a portaria remeter ao texto da lei sugere que ela está
em pleno vigor, apesar de ser, evidentemente, contrária
à norma constitucional da liberdade sindical. A portaria
pode ser encontrada em http://portal.mte.gov.br/data/fi-
les/8A7C816A4A5E01F7014A5E52BD48264E/Port._186_-
de_29.01.014.pdf (acessado em junho de 2015).
12 Dados em http://www3.mte.gov.br/sistemas/cnes/relato-
rios/painel/GraficoTipo.asp, acessado em janeiro de 2015.
13 Agradeço a Pascoal Carneiro, Secretário Geral da CTB,
que gentilmente me enviou os microdados do CNES, cujo
acesso via site do MTE é muito pouco amigável.


milhões de filiados declarados pelos sindicatos estavam bem aquém dos 15 milhões encontrados pela PNAD em 2013. O número "real" de filiados deve estar em algum lugar entre essas duas cifras, mas não há como decidir por uma ou por outra.

Dos 8.1 milhões de filiados que os sindicatos declararam possuir em 2013, metade estava nos sindicatos de empregados urbanos, e um quinto em sindicatos de servidores públicos (Tabela 1). Note-se que essas duas categorias filiavam, proporcionalmente, mais do que as outras (com exceção dos sindicatos de "categorias diferenciadas”) vis-à-vis sua participação no total de sindicatos existentes. Isso fez com que as entidades dessas duas categorias fossem, em média, "maiores" do que as das demais: sindicatos de empregados filiavam, em média, 936 pessoas, e de servidores públicos, 1.024.

As médias, pois, são muito baixas em todas as categorias, principalmente se consideramos que havia cerca de 2.5 mil sindicatos estaduais em 2013. Estes tinham, em média, pouco mais de mil filiados. Havia, também, dezenas de sindicatos interestaduais e quase 50 sindicatos nacionais. Mesmo entre estes últimos, a média de filiados era muito baixa, de menos de quatro mil trabalhadores.

م0

Tabela 1 - Sindicatos de trabalhadores registrados no MTE, segundo tipo de sindicato e proporção de trabalhadores filiados. Brasil, 2013

\begin{tabular}{|c|c|c|c|}
\hline Tipo de Sindicato & $\begin{array}{l}\text { Prop. de } \\
\text { sindicatos }\end{array}$ & $\begin{array}{l}\text { Prop. dos } \\
\text { filiados }\end{array}$ & $\begin{array}{c}\text { Média de } \\
\text { associados }\end{array}$ \\
\hline Empregados & 44,2 & 52,1 & 936 \\
\hline Servidores públicos & 15,8 & 20,4 & 1.024 \\
\hline Rurais & 26,9 & 18,2 & 538 \\
\hline Categoria Diferenciada & 4,6 & 4,7 & 809 \\
\hline Profiss. Liberais & 4,0 & 3,0 & 591 \\
\hline Autônomos & 2,3 & 1,0 & 338 \\
\hline Trabs Avulsos & 2,1 & 0,6 & 215 \\
\hline Total & 10.222 & 8.117 .500 & 794 \\
\hline
\end{tabular}

Fonte: Tabulado a partir dos microdados do CNFS/MTE

Ainda assim, é digno de nota que mudanças no âmbito da lei tenham estimulado um novo processo de alinhamento do "mercado sindical" no país, fazendo com que a maioria dos sindicatos existentes se filiasse a uma das centrais que disputam a lealdade das entidades de base. Com efeito, em 2001, ano do último censo sindical do IBGE, apenas 38\% dos sindicatos se haviam declarado filiados a uma das centrais então existentes, e destes, $66 \%$ eram filiados à Central Única dos Trabalhadores (CUT). Já entre os sindicatos ativos de trabalhadores em 2015, 74\% eram filiados a uma das centrais, e dos trabalhadores a eles filiados, 31,7\% estavam na CUT, 10,8\% na Força Sindical, 10,4\% na Central dos Trabalhadores e Trabalhadoras do Brasil (CTB), 10,3\% na União Geral dos Trabalhadores (UGT), 7,7\% na Nova Central Sindical dos Trabalhadores (NTSC) e 7,2\% na Central dos Sindicatos Brasileiros (CSB). Portanto, seis dentre as doze centrais sindicais existentes tinham 7\% ou mais dos trabalhadores filiados, limite legal exigido para acesso ao imposto sindical.

A disputa pelo imposto tornou o ambiente sindical ainda mais competitivo, com entidades mudando de mãos em eleições concorridas, fruto da competição entre as instituições de cúpula. Isso sempre ocorreu no país, mas o expressivo crescimento da Força Sindical até 2013, saltando de perto de 800 em 2001 para mais de 1.600 sindicatos filiados, e o relativo esvaziamento da CUT no período, que perdeu entidades para centrais dissidentes e, também, para a Força Sindical, ${ }^{14}$ não podem ser explicados sem referência a essas mudanças legais, que passaram a orientar a ação estratégica das entidades de cúpula. ${ }^{15}$ Nesse âmbito específico (movimentação de lideranças, alinhamentos políticos, disputas em eleições acirradas etc.), não se pode dizer que o sindicalismo brasileiro esteja inerte. Temos, então, um aparente paradoxo: sindicatos de base esvaziados de adeptos e cú-

${ }^{14}$ A CUT tinha 2.8 mil sindicatos filiados em 2001, segundo o Censo Sindical do IBGE, e 2.2 mil em 2013, segundo o CNES.

${ }^{15} \mathrm{O}$ dado para a Força em 2001 é do Censo Sindical do IBGE. 
pulas sindicais em grande atividade organizativa. Voltarei ao tema mais adiante.

\section{Ação coletiva}

O esvaziamento dos sindicatos estaria afetando sua capacidade para a ação coletiva? Quem participa de congressos sindicais está acostumado a ouvir lamentações de lideranças descontentes com os rumos do sindicalismo no país. O que mais se ouve é "onde estão os sindicatos, que não fazem mais greves?”. Ou “o sindicalismo não tem mais a importância que teve nos anos 1980, a gente não escuta mais falar em greves, mobilizações [...]”. Até que ponto essas impressões têm base nos fatos?

No dia 11 de julho de 2013, uma quintafeira normal de trabalho, o sindicalismo e outros movimentos sociais levaram mais de 100 mil pessoas às ruas em mais de 100 cidades do país, pedindo redução de jornada de trabalho e fim do fator previdenciário, dentre outros temas menos relevantes. São números expressivos, embora eclipsados pelas "jornadas de junho”, que tinham levado às ruas um milhão de pessoas um mês antes. Mas, medir o fracasso de um movimento pelo sucesso do outro não é adequado. A pauta sindical não era a pauta dos manifestantes de junho. E, ao contrário do que quis a cobertura da grande imprensa, não era uma pauta "antiga”, "velhusca”, porque vinculada ao mundo do trabalho assalariado, portanto coisa do século passado, enquanto o "novo" seria a celebração da democracia direta, etc.

Jornada de trabalho e regras de aposentadoria, os dois temas mais salientes da convocação das centrais sindicais, são mais abrangentes do que parece, afeitos a todos os que ganham a vida trabalhando. De acordo com os dados da PNAD 2013, 59 milhões de brasileiros contribuíam para a previdência social, e cerca de 130 milhões de pessoas viviam em famílias nas quais pelo menos um membro contribuía. Além disso, 40 milhões de brasileiros trabalhavam 44 horas por semana ou mais, e 110 milhões de pessoas viviam em famílias nas quais pelo menos um membro trabalhava 44 horas ou mais por semana. Trabalhar menos e se aposentar com decência são conquistas civilizatórias universalizadas no século XX nos países mais ricos, mas que permanecem uma promessa no Brasil. E são demandas históricas de nosso sindicalismo.

Do mesmo modo, em 15 de abril de 2015, a maioria das centrais sindicais, juntamente com o Movimento dos Trabalhadores Rurais Sem Terra (MST), levou novamente mais de 100 mil pessoas às ruas e coordenou greves em todo o país em protesto contra a votação do Projeto de Lei 4330/04, que regulamenta as terceirizações no Brasil, liberando-as para toda e qualquer relação de emprego. O movimento, culminância de intensa mobilização através da imprensa, das redes sociais e das próprias organizações, que incluiu abaixo assinados e protestos no Congresso Nacional, foi considerado bem sucedido e massivo pelos meios de comunicação. ${ }^{16}$

No caso de julho de 2013, levar $100 \mathrm{mil}$ pessoas às ruas numa quinta-feira normal de trabalho não é feito de somenos, embora tenha sido menosprezado pela grande mídia e também pela academia. Note-se que os sindicalistas não foram às ruas para protestar contra o governo ou o Congresso, como foi o caso dos movimentos de junho de 2013. Eles foram às ruas para tentar colocar temas sindicais na pauta dos protestos. Fizeram-no, ademais, como demandas ao Congresso Nacional, instituição democrática responsável pela elaboração das leis trabalhistas e previdenciárias. O ${ }^{16}$ O Jornal Nacional, da Rede Globo, organização favorável ao PL4330/04, alocou quatro minutos e 28 segundos ao tema, sendo um quarto do tempo dedicado aos protestos (pintados como exitosos), dois quartos trazendo opinióes favoráveis ao projeto e outro quarto com a cobertura da votação no Congresso. Curioso que a Folha de S. Paulo não tenha destinado uma linha sequer aos protestos ou à votação do dia 15 de abril, que acabou sendo adiada para a semana seguinte. O Estado de S. Paulo noticiou os protestos em $2 / 3$ da página 26 , sem chamada na capa. E o jornal O Globo os noticiou em dois pequenos parágrafos da meia página (p. 23) que dedicou à votação do PL4330/04. A pequena cobertura, porém, deixa claro o êxito da mobilização, ocorrida em 23 estados e no Distrito Federal. Os acervos dos quatro veículos de comunicação estão disponíveis na internet. 
movimento sindical não negou o Congresso ou a política, como boa parte dos movimentos de junho. Ao contrário, interpelou o mundo da política institucional, visando interferir no conteúdo de sua pauta de prioridades. Movimento, portanto, que reconheceu no Congresso lugar legítimo de exercício de poder numa democracia representativa. E, mesmo os protestos de 2015 visavam mudar os rumos da votação do PL4330/04, pressão que se mostrou momentaneamente bem sucedida, já que o presidente da casa, Eduardo Cunha, suspendeu a sessão ao perceber que não teria os votos necessários à aprovação do projeto. ${ }^{17}$

Voltemos às greves. Sempre segundo o DIEESE, a partir de 2007 vem ocorrendo aumento quase contínuo no número de greves no país, até atingir a cifra de 1.901 casos em 2013 (Gráfico 2). A mesma fonte informa que 55\% das paredes daquele ano tinham ocorrido em empresas privadas, e 38\% na administração pública, sendo $62 \%$ delas greves de servidores municipais. Foi o maior volume de greves em 22 anos (isto é, desde 1991), e, considerando o período coberto pelas estatísticas do DIEESE (1980 em diante), esteve abaixo, apenas, do momento mais conturbado dos anos 1980 (1987-1990), que fez do Brasil o campeão mun-

Gráfico 2 - Número de greves no Brasil, 2001-2013

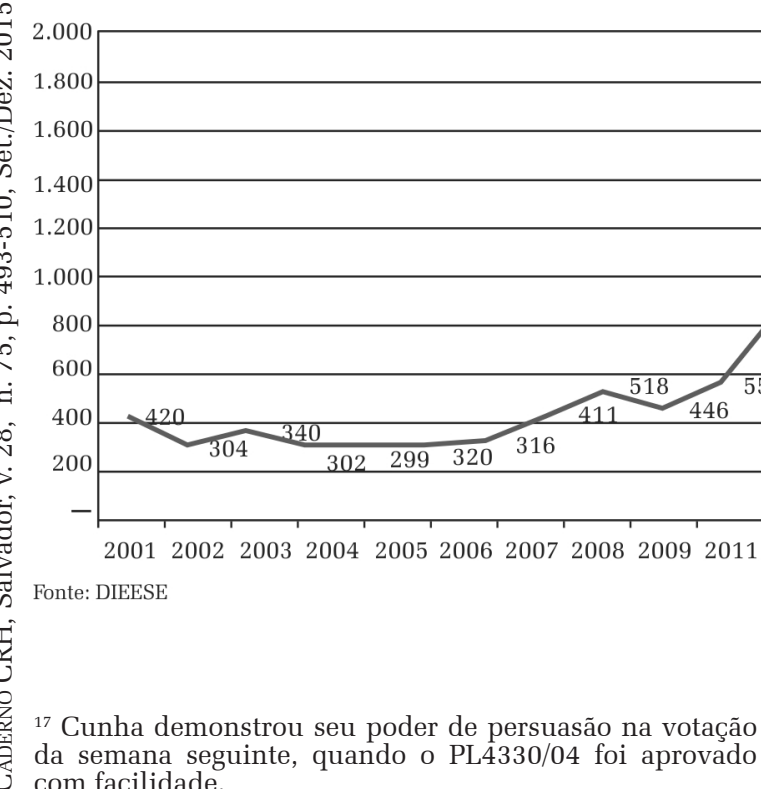

com facilidade. dial de jornadas perdidas (Noronha, 1994).

Os dados do DIEESE apontam, ainda, que $75 \%$ das greves de 2012 podem ser consideradas vitoriosas, ${ }^{18}$ já que tiveram as reivindicações atendidas no todo ou em parte, e em $34 \%$ dos casos as negociações prosseguiriam após a greve. ${ }^{19} \mathrm{E}$ fato inconteste que as greves, mesmo quando volumosas, como em 2013, já não têm o impacto político dos anos de renascimento do sindicalismo entre nós, mas elas não estão ausentes do cenário das lutas sindicais, e não são nem ineficazes nem inexpressivas, como mostram os dados do DIEESE.

Nesse pormenor, não há como discordar de Noronha (2009) quanto ao fato de que o ciclo de greves dos anos 1980 deve ser tomado como excepcional, já que não há equivalente na história do país. Aqueles foram anos de ressurgimento do sindicalismo, luta pela democratização, construção institucional das centrais sindicais e de partidos ligados aos trabalhadores, agitação em torno da Assembleia Constituinte, crise do Estado, resultando no vilipêndio dos salários dos servidores públicos, responsáveis pela maior parte das jornadas de trabalho perdidas etc. A estabilidade democrática e a crise dos anos 1990 provocaram uma queda, seguida de estabilização no ímpeto grevista, que, contudo, jamais deixou a cena sindical do país. O que ele perdeu, e, como mostraram os protestos e greves de abril de 2015, perdeu apenas em parte, foi seu caráter expressivo e de massa, aspectos que ajudaram a construir a identidade do movimento sindical no país nos anos 1980. Uma identidade que, para se fazer valer, precisou se mostrar com estardalhaço na cena pública, a qual era, também, uma arena de disputa política sobre os destinos da nação, que estavam sendo jogados a todo momento nos meandros da transição

${ }^{18}$ No momento em que escrevo o DIEESE ainda não publicou os dados detalhados para 2013.

19 Dados em http://www.dieese.org.br/balancodasgreves/2012/estPesq66balancogreves2012.pdf, p. 19 (acessado em janeiro de 2015). 
do autoritarismo. As greves, hoje, têm caráter sobretudo instrumental, já que utilizadas como recurso de poder nas negociações coletivas. E têm sido eficazes nesse aspecto, ao menos em termos salariais.

De fato, nos anos 1990, as negociações salariais tinham sido, quase sempre, desfavoráveis aos trabalhadores (Tabela 2), e, mesmo os sindicatos mais fortes do país, foram obrigados a negociar perdas de direitos contratuais conseguidos ao longo da década anterior (Cardoso, 2003). Desemprego em alta, ameaça de migração por parte das empresas, reestruturação produtiva, flexibilização dos contratos de trabalho, crescimento da informalidade, desindustrialização dos empregos, tudo isso reduziu, e muito, o poder de barganha dos sindicatos, que, ademais, perderam base de sustentação em razão da redução dos empregos formais.

Nos anos 2000, o cenário mudou substancialmente. Em 2008 foram depositados no Ministério do Trabalho 32 mil acordos e convenções coletivas. Esse número foi equivalente

Tabela 2 - Dissídios coletivos na Justiça do Trabalho Brasil, 1941 a 2014*

\begin{tabular}{|c|c|c|c|}
\hline Anos & & $\begin{array}{l}\text { Dissídios } \\
\text { Julgados }\end{array}$ & $\begin{array}{r}\text { Média } \\
\text { anual }\end{array}$ \\
\hline 1941 & -1945 & 191 & 38 \\
\hline 1946 & -1950 & 1.175 & 235 \\
\hline 1951 & -1955 & 1.659 & 332 \\
\hline 1956 & -1960 & 2.339 & 468 \\
\hline 1961 & -1965 & 4.082 & 816 \\
\hline 1966 & -1970 & 3.740 & 748 \\
\hline 1971 & -1975 & 4.828 & 966 \\
\hline 1976 & -1980 & 5.417 & 1.083 \\
\hline 1981 & -1985 & 4.120 & 824 \\
\hline 1986 & -1990 & 8.811 & 1.762 \\
\hline 1991 & - 1995 & 12.486 & 2.497 \\
\hline 1996 & -2000 & 4.676 & 935 \\
\hline 2001 & -2005 & 3.429 & 686 \\
\hline 2006 & -2010 & 3.979 & 796 \\
\hline 2011 & -2014 & 2.503 & 501 \\
\hline Total & & 63.435 & \\
\hline
\end{tabular}

Fonte: Tribunal Superior do Trabalho.

* Agradeço a Sandro Magnos Karkow, do TST, o envio dos dados sobre movimento processual. ao encontrado pelo Censo Sindical do IBGE de 2001, já mencionado, e, antes, em 1991 (Cardoso, 1999). São valores típicos, portanto. Não há razão para imaginar que a cifra tenha diminuído desde então, numa situação de retomada do ímpeto grevista. O volume de eventos de negociação é, há décadas, portentoso. Isso quer dizer mobilização regular de energias de dirigentes sindicais e seus advogados em todo o país, bem como de sindicatos patronais e diretorias de recursos humanos das empresas, na negociação de acordos e convenções que regerão a vida dos milhões de trabalhadores representados. E isso ocorre mesmo que estes não se deem conta, já que a representação é compulsória e as taxas de filiação, baixas. A negociação coletiva é ainda mais invisível do que as greves instrumentais, mas seu exercício regular expõe um aspecto que costuma passar despercebido pelos analistas: em 1967, a Lei brasileira tornou a negociação coletiva obrigatória (Silva, 2008), e, enquanto for assim, teremos sindicatos ativos negociando condições contratuais para seus representados.

Ressalte-se que as negociações coletivas no Brasil ocorrem, hoje, num ambiente de autocomposição do conflito de classe, isto é, com interferência mínima da Justiça do Trabalho (DIEESE, 2006). Mais do que isso, a interferência parece ter sido, historicamente, bem menor do que se supõe. Como mostra a Tabela, até meados dos anos 1970, a média anual de dissídios coletivos julgados pela JT em todo o país esteve sempre abaixo de mil casos. Esse dado pode parecer paradoxal, já que a literatura clássica sobre o tema (Erickson, 1979; Schmmitter, 1971; Martins Rodrigues, 1974; Martins, 1989) coloca o judiciário trabalhista como ator central das relações coletivas de trabalho entre nós, principalmente no período da ditadura civil-militar de 1964, quando a negociação coletiva dos reajustes salariais estava virtualmente proibida (Silva, 2008). Mas o fato é que, mesmo nos anos de pico de soluções judiciais dos conflitos (1991-1995, com média de quase 2.5 mil dissídios anuais), a propor- 
ção delas não ultrapassou $8 \%$ do total de negociações coletivas, estando, na maioria dos outros anos, bem abaixo dos 4\% (considerando a média aproximada de 30 mil negociações

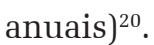

A negociação coletiva entre nós, portanto, é assunto para os próprios interessados, capital e trabalho. E, uma vez mais, segundo o DIEESE, desde 2008, 80\% ou mais das categorias negociaram reajustes salariais acima da inflação, proporção que atingiu quase 95\% em 2012. ${ }^{21}$ Apesar da queda em 2013, em 2014 a cifra voltou a superar os 90\%. Desde 2005, a proporção de acordos que superaram a inflação esteve sempre acima de $70 \%$, e acima de $80 \%$ na maioria das vezes (Tabela 3 ).

Vistos em conjunto, os dados sobre greves e negociação coletiva sugerem que, embora "invisível" (pois não provoca a mesma comoção de outros tempos), a ação sindical no Brasil parece bastante eficaz ali onde os sindicatos são convocados cotidianamente para negociar

Tabela 3 - Negociações coletivas com reajuste salarial acima do INPC. Brasil, 1996-2012

\begin{tabular}{|c|c|}
\hline Anos & $\begin{array}{l}\text { Proporção com } \\
\text { reajustes acima } \\
\text { do INPC }\end{array}$ \\
\hline Média 1996 - 2003 & 38,6 \\
\hline 2004 & 54,9 \\
\hline 2005 & 71,7 \\
\hline 2006 & 85,7 \\
\hline 2007 & 87,7 \\
\hline 2008 & 78,3 \\
\hline 2009 & 80,5 \\
\hline 2010 & 87,8 \\
\hline 2011 & 87,1 \\
\hline 2012 & 94,6 \\
\hline 2013 & 86,2 \\
\hline 2014 & 91,5 \\
\hline \multicolumn{2}{|l|}{ Fonte: DIEESE } \\
\hline \multicolumn{2}{|c|}{$\begin{array}{l}{ }^{20} \text { A historiografia sobre a Justiça do Trabalho vem mos- } \\
\text { trando a importância relativa de seu poder normativo e } \\
\text { dos dissídios coletivos nas relaçóes de classe no Brasil, } \\
\text { em especial no pré-1964. Ver Silva (2013) e Corrêa (2011). } \\
\text { Ver também http://www.ifch.unicamp.br/cecult/dissidios/, } \\
\text { banco de dados sobre dissídios coletivos na JT. O banco } \\
\text { vem sendo alimentado lentamente, mas já há, enquanto } \\
\text { escrevo, } 1.4 \text { mil documentos catalogados para o período } \\
\text { 1963-67. }\end{array}$} \\
\hline $\begin{array}{l}{ }^{21} \text { Dados em } h \\
\text { tes/2014/estPesc }\end{array}$ & $\begin{array}{l}\text { ese.org.br/balancodosreajus- } \\
\text { 014.pdf. }\end{array}$ \\
\hline
\end{tabular}

os interesses de seus representados junto aos patrões. Nesse âmbito, não há crise sindical visível. E isso, num ambiente no qual é cada vez mais baixa a proporção de trabalhadores que aderem às suas entidades, expressa pelas taxas cadentes de filiação sindical.

\section{CRISE DE UM PROJETO POLÍTICO?}

A ideia de crise do sindicalismo encapsula, na verdade, um espírito do tempo. O movimento sindical brasileiro teria perdido a capacidade de nuclear projetos políticos mais amplos, de capturar o novo, de mediar os anseios emergentes da população trabalhadora (como, por exemplo, os expressos nas "jornadas de junho" de 2013). Teria, ainda, exaurido as energias utópicas que animaram revoluções ou processos de reforma ou "humanização" do capitalismo, tornando-se apenas pragmático, ou instrumental. Mais ainda, não são poucos os analistas que atribuem a "crise" (que não está tão visível nos números, mas é percebida por todos) à cooptação das lideranças mais importantes do movimento pelos governos sucessivos do Partido dos Trabalhadores. Concordo apenas em parte com esses diagnósticos.

Desenvolvi em outro lugar (Cardoso, 2010), um longo argumento sobre a especificidade da construção da sociedade do trabalho no Brasil, e do papel desempenhado, nesse processo, pela regulação do mercado de trabalho, que capturou as energias, corações e mentes dos trabalhadores que migraram aos milhões do campo para a cidade a partir dos anos 1940. Mostrei que a Consolidação das Leis do Trabalho, ao ser decretada, constituiu um ambiente de disputa, por sua validade no dia a dia das relações de trabalho, e estabeleceu os parâmetros da ação coletiva dos trabalhadores, voltada para a efetivação dos direitos, ação por muito tempo mediada pela Justiça e o Ministério do Trabalho. Os sindicatos se fortaleceram na luta pelos direitos trabalhistas, que tinham uma dimensão utópica irrecusável para traba- 
lhadores miseráveis, que fugiam do campo em busca de melhoria de vida, atraídos também pelos direitos. Além disso, em Cardoso (2014), argumentei que Lula e o Partido dos Trabalhadores cumpriram, finalmente, a profecia Varguista, que previu que os trabalhadores um dia seriam o governo, e dariam à acumulação capitalista condições socialmente menos turbulentas para prosperar. ${ }^{22}$ Os governos Lula devem ser pensados como o ponto de chegada de projetos de inclusão nutridos por várias gerações de brasileiros, num processo histórico que reprimiu e destruiu alternativas utópicas não capitalistas de organização social. A assunção de Lula ao poder federal em 2003 materializou a utopia brasileira do trabalho regulado, não podendo ser considerada o esgotamento de suas energias, mas sim, seu ponto culminante.

Nesse quadro, pareceu-me, e ainda me parece, despropositado tratar como cooptação do movimento sindical a história de sucesso de um projeto político que uniu, desde o berço, o PT, a CUT e um conjunto amplo de movimentos sociais ao longo da história. A CUT ou a Central dos Trabalhadores Brasileiros (CTB, dissidência da CUT ligada ao Partido Comunista do Brasil, PCdoB) não foi "cooptada". Bem ao contrário: o projeto político alimentado pela CUT, ou pelas facções majoritárias da central, chegou ao poder federal em 2003 com o PT. Lula levou com ele algumas centenas de lideranças cutistas e comunistas, colocadas em postos estratégicos de gestão do Estado. Não me refiro apenas aos canais de participação criados pela Constituição de 1988 (como os vários conselhos consultivos ou deliberativos que hoje povoam o aparato estatal), ativados de forma sem precedentes sob Lula e que incluíram, também, as outras centrais (Pires,

${ }^{22}$ Num conhecido discurso proferido por Getúlio Vargas em 1954, três meses antes de se suicidar, dirigindo-se aos trabalhadores ele disse que "hoje vocês estão com o governo, amanhã vocês serão o governo" (Vargas, 1969, p. 473). Ele profetizava com base na sua avaliação sobre as transformações pelas quais passava o Brasil, com a intensa urbanização e com o início da construção de uma classe operária urbana que, imaginava-se no seu tempo, um dia seria a maioria da população, já que a nação estava se industrializando e modernizando.
2011). Refiro-me propriamente à gestão do Estado, aos postos ocupados na administração direta e indireta por Antônio Palocci, Luís Marinho, Luís Gushiken, Jaques Wagner, Wilson Santarrosa, Ricardo Berzoíne, Jair Meneguelli... Pode-se gastar muita tinta nomeando as pessoas que ocuparam os vários escalões do poder de Estado, egressas da CUT e dos movimentos sociais. Sem contar que 44 dos 91 deputados federais eleitos em 2002 pelo PT tinham origem no movimento sindical (Lucca, 2011). A CUT não foi cooptada pelo governo. Ela chegou ao poder com Lula e tornou-se importante manancial de novas elites, agora de extração popular, com lastro no mundo do trabalho, aptas à gestão do Estado capitalista.

Essa coalisão e esse projeto político estão, obviamente em crise. Mas é preciso distinguir, analiticamente, a "crise" propriamente sindical, que, de meu ponto de vista, resulta também das escolhas estratégicas de suas principais lideranças (e não apenas de injunções estruturais), da crise política ora vivida, que é profunda e afeta todo o campo sindical e a esquerda de um modo geral. Muito do diagnóstico sobre a crise do sindicalismo decorre da não atenção a esses dois momentos da dinâmica global do movimento. Vejamos.

\section{Oligarquização}

Em termos propriamente organizacionais, o dado obviamente mais saliente é a queda expressiva na densidade sindical nos últimos anos. Entre 2012 e 2013, houve inclusive perda absoluta de adeptos, algo que, desde que o IBGE incluiu a pergunta sobre filiação na PNAD em 1988, havia se passado apenas entre 1996 e 1998, anos de altíssimas taxas de desemprego aberto (Pochmann, 2001). A queda recente, ao contrário, ocorreu num momento de baixíssimo desemprego e de crescimento importante do emprego formal (DIEESE, 2014). Por que os sindicatos estão com dificuldades para atrair novos adeptos, num mercado de trabalho em expansão? 
Parte da explicação está, justamente, na expansão acelerada dos empregos, associada às altas taxas de rotatividade, como mostrou Pochmann (2012). O mercado de trabalho apresentou, no período, movimentos concomitantes de criação de postos de trabalho, atraindo novos entrantes, e substituição de trabalhadores há mais tempo nos empregos, através do aumento da rotatividade. Além disso, os novos postos gerados são, em sua maioria, de má qualidade, com remuneração de dois salários mínimos ou menos em $80 \%$ dos casos, e eles também apresentam altas taxas de rotatividade. ${ }^{23}$ Empregos instáveis e mal remunerados não são bom terreno para a filiação a sindicatos.

Esse elemento estrutural tem, sem dúvida, relevância na explicação da queda na densidade sindical, mas não explica tudo. Um segundo aspecto de relevo tem a ver com o relativo abandono do projeto de renovação da estrutura sindical, alimentado por várias correntes até os anos 1990, projeto que previa o fim do imposto sindical, o que obrigaria os sindicatos a buscar se financiar, por exemplo, com a associação voluntária de membros. A CUT, desde aquela década, orienta seus sindicatos a se sustentar apenas com a contribuição voluntária dos associados, e é crescente o número de entidades que devolvem o imposto sindiเo cal. Os sindicatos de bancários de Curitiba e సे de São Paulo, por exemplo, devolvem, mas, no Фं caso de Curitiba, o fazem apenas aos sindicalizados. $^{24}$ É o caso também do Sindicato Nacional dos Aeronautas, que decidiu, numa as-

மم ${ }^{23}$ Isso explica, por exemplo, o paradoxo de termos a maior - taxa de criação de empregos formais na história recente do ¿ país e, ao mesmo tempo, um aumento sem precedentes na $\infty$ o concessão do seguro desemprego, o que contribuiu para a

$\checkmark$ deterioração das contas do Fundo de Amparo ao Trabalha-

dor, responsável pelo pagamento do seguro e também do

ồ abono salarial.

24 Ver http://www.bancariosdecuritiba.org.br/noticias-interna/5/geral/21468/saiba-mais-sobre-a-devolucao-do-im- posto-sindical-2015 para os bancários de Curitiba, e http:// cut.org.br/noticias/bancarios-de-sp-podem-solicitar-devolucao-do-imposto-sindical-a-partir-do-dia-22-fb7a/, para o caso dos de São Paulo (acessados em junho de 2015).

25 Ver http://www.aeronautas.org.br/assembleia-aprovadevolucao-da-contribuicao-sindical-saiba-como-proceder/ mais comum nos sindicatos de servidores públicos, que, tradicionalmente, se sustentavam com contribuições voluntárias, já que até 1988 não podiam existir como sindicatos oficiais. ${ }^{26}$ Seja como for, a devolução do imposto ainda é a exceção, não a regra entre os 11 mil sindicatos existentes, e, em geral, favorece apenas os associados.

Esse poderia ser um estímulo importante ao aumento do número de associados, interessados nos recursos compulsoriamente descontados de seus salários a cada ano, mas não parece ser o caso, já que a proporção de filiados vem caindo, mesmo com o aumento do número de entidades que devolve o imposto. Vale lembrar que este último equivale a um dia de salário por ano, descontado uma única vez, enquanto a filiação implica o pagamento de mensalidades. Se movidos por cálculo racional, os trabalhadores preferirão o imposto à filiação. Sem falar no paradoxo de que, quanto menor o número de associados, menos impostos terão de devolver os sindicatos que adotam como regra estender o benefício apenas aos filiados. Por fim, a lei de 2008, que destinou $10 \%$ do imposto às centrais sindicais, ajudou a arrefecer o ânimo das lideranças de cúpula. Embora a CUT oriente seus sindicatos a devolver o imposto, ela mesma não o faz.

Outro elemento que ajuda a explicar o pequeno apelo da devolução do imposto junto à massa das lideranças sindicais é a jurisprudência da Justiça do Trabalho, que julga inconstitucional a extensão das contribuições não previstas em lei (como a contribuição confederativa ou a contribuição negocial, regularmente acordadas nas negociações coletivas) aos membros não associados das categorias. ${ }^{27}$

(acessado em junho de 2015).

${ }^{26}$ A APEOESP, sindicato do professorado paulista, e seu congênere mineiro, o Sindute, foram pioneiros na devolução do imposto. A prática está crescendo, também, entre os sindicatos de metalúrgicos (ABC, São José dos Campos, Taubaté, Limeira, Campinas, Santo André e outros, nem todos filiados à CUT, que defende programaticamente a devolução).

${ }^{27}$ Ver a Orientação Jurisprudencial SDC $\mathrm{n}^{\circ} 017$, do Tribunal Superior do Trabalho (TST) em http://www.jurisway. org.br/v2/sumula.asp?pagina $=11$ \&idarea $=1$ \&idmode- 
A JT considera a extensão automática dessas contribuições contrária à liberdade de associação a sindicatos. Isso torna os sindicatos com poucos associados ainda mais dependentes do imposto, que acaba sendo sua principal fonte de renda. E mesmo esse incentivo seletivo ao aumento do número de associados (aos quais se aplicariam as contribuições negociadas em convenção coletiva) não tem sido suficiente. $\mathrm{O}$ número de associados vem caindo, como vimos, e, se o cenário de 1996 a 1998 se repetir, com aumento do desemprego em razão da crise econômica, tende a cair mais.

Tudo isso sugere que os sindicatos deveriam tentar atrair adeptos em outras bases que não o cálculo racional relacionado aos custos monetários da filiação. A história do sindicalismo oferece como alternativa mais comum a construção de solidariedade e identidade de categoria ou classe. Mas a dificuldade parece estar justamente nisso: construir uma prática sindical com apelo à solidariedade e à participação, que leve os trabalhadores a se sentirem representados por suas entidades de classe ao ponto de se cotizarem para sustentá-las.

É possível identificar, nas múltiplas faces do ordenamento sindical, elementos que conspiram contra esse objetivo. Em primeiro lugar, já se disse que a negociação coletiva é obrigatória no Brasil desde a reforma trabalhista de 1967. Logo, sem mudança legal, os sindicatos continuarão a ter existência obrigatória. Isso torna legítima a demanda por uma forma regular e também obrigatória de financiamento, como o imposto sindical, com isso dificultando sua extinção. As centrais sindicais, por sua vez, para terem acesso ao imposto, precisam filiar esses sindicatos, e essa legislação é recente. Ela, na verdade, assegura um mecanismo duradouro e regular de produção de elites sindicais aptas à ação política e, eventualmen-

lo=4779 (acessado em abril de 2015), segundo a qual "As cláusulas coletivas que estabeleçam contribuição em favor de entidade sindical, a qualquer título, obrigando trabalhadores não sindicalizados, são ofensivas ao direito de livre associação e sindicalização, constitucionalmente assegurado, e, portanto, nulas, sendo passíveis de devolução, por via própria, os respectivos valores eventualmente descontados". te, à gestão do Estado, sempre que forças políticas ligadas aos sindicatos chegarem ao poder, nas várias instâncias federativas. Logo, dificilmente será mudada ou combatida pelas forças hoje no comando do governo federal, mesmo que a CUT seja programaticamente contra o imposto e oriente seus filiados a devolvê-lo.

Esse ordenamento favorece a continuidade da fragmentação da representação sindical na base, com criação de novos sindicatos, aliada ao crescimento concomitante das centrais sindicais. A imagem destas como gigantes com pés de barro é, hoje, mais do que provável. É um fato. Dez por cento do imposto sindical é, hoje, dividido entre seis centrais sindicais, ${ }^{28}$ enquanto $60 \%$ é dividido entre quase 11 mil sindicatos. Em 2014, a CTB, por exemplo, tinha não mais que 750 mil trabalhadores filiados aos 680 sindicatos que representava, mas tinha direito a 9,3\% do imposto destinado às centrais, ou perto de R\$12 milhões. Valor superior ao que partidos como PV, PPS, PCdoB ou PSOL receberam do fundo partidário no mesmo ano. ${ }^{29}$ A CUT, com seus 2.8 milhões de trabalhadores filiados aos 2.2 mil sindicatos que representava, recebeu mais de $\mathrm{R} \$ 55$ equivalente ao que os maiores partidos, $\mathrm{PT}$ e PMDB, receberam do fundo partidário no mesmo ano. ${ }^{30}$

De posse de fonte segura de recursos de vulto, a competição entre elas, que já é intensa, tende a aumentar. Caso saliente é o da Central dos Sindicatos Brasileiros (CSB), que, na aferição de 2015, com base em dados de 2014,

${ }^{28}$ Escrevo "hoje” porque, em 2014, eram cinco as centrais que se qualificavam. A CSB não constava do rol enumerado mais acima.

${ }^{29} \mathrm{O}$ fundo partidário é rateado entre os partidos segundo sua representação na Câmara Federal. A dotação mensal para 2014 pode ser encontrada em http://www.justicaeleitoral.jus.br/arquivos/tse-distribuicao-do-fundo-partidarioduodecimos-2014. (acessado em julho de 2015).

${ }^{30}$ O jornal O GLOBO publicou uma série de reportagens sobre os sindicatos no Brasil nos dias 20, 21 e 22 de julho de 2015. O noticiário é, obviamente, contra os sindicatos, pintados como corruptos e vorazes, e faz parte da estratégia das organizações Globo de minar as bases sociais dos governos do PT. Mas os dados sobre o financiamento das centrais sindicais apresentados na reportagem do dia 20 , reproduzidos aqui, são oficiais, fornecidos pela Caixa Econômica Federal, responsável pelo repasse dos recursos do imposto às entidades sindicais. 
acedeu à elite das que têm direito ao imposto por meio da adesão de novos sindicatos e do aumento da taxa de filiação sindical nas entidades existentes. Em 2013, por exemplo, a média de filiados era de 667 pessoas nos 363 sindicatos representados pela CSB, subindo a 1039 trabalhadores em 2014, filiados em 423 sindicatos. CUT, Força Sindical e NCST perderam sindicatos para a nova central fundada em $2008 .^{31}$

O mais curioso é que, mesmo havendo estímulo para a luta por adeptos por parte dos sindicatos de base, já que esse é o critério usado pelo MTE para ratear os 10\% do imposto sindical, com exceção da CSB, as centrais não vêm conseguindo aumentar a média de trabalhadores filiados. Ou seja, a competição entre elas está ocorrendo, mesmo num ambiente de baixa filiação sindical, que, ademais, não é necessária para que a estrutura que reproduz as lideranças de base sobreviva e prospere. É possível haver sindicatos com muito poucos filiados, que negociam coletivamente em nome das bases que legalmente representam e alimentam o sistema como um todo com lideranças e militantes. Logo, é interesse dos sindicalistas de base manter a filiação baixa, para, com isso, ter mais controle sobre as eleições e sobre os mecanismos de reprodução de seu poder.

É evidente o risco de oligarquização 늘 crescente do movimento, por meio do coni trole, cada vez maior, pelas ricas centrais sinهं dicais, desses mecanismos de reprodução de quadros. De posse de recursos financeiros $\therefore$ polpudos, elas tendem a ser força importante

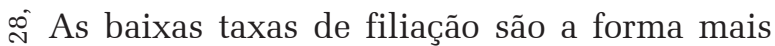
$\dot{s}$ segura de controlar as eleições, ou de restringi-las a eleitores confiáveis, com isso reduzindo o risco de perda das entidades, cujo controle garante acesso ao imposto sindical. Fecha-se, com isso, um círculo de interesses investidos, cuja consequência é maior fragmentação (sin${ }^{31}$ A fonte é sempre os microdados do CNES. dicatos menores, mas em maior número), que enfraquece a representação de base, ao passo em que fortalece os organismos de cúpula. E são estes que têm assento nos mecanismos decisórios criados pela Constituição de 1988, e são eles que falam em nome dos trabalhadores na esfera pública.

\section{O projeto político}

Parte da dificuldade de os sindicatos reconstruírem a solidariedade necessária à atração de adeptos em bases mais duradoras decorre, também, da perda de confiança nas instituições brasileiras em geral e nos sindicatos em particular. Em 1990, logo depois das eleições presidenciais que quase levaram Lula ao poder, o IBOPE entrevistou 3.6 mil eleitores, e, dentre as perguntas do questionário, estava o grau de confiança nas instituições. No caso dos sindicatos, 56\% dos eleitores declararam ter muita ou alguma confiança, ficando abaixo apenas da Igreja Católica (82\%) e do Supremo Tribunal Federal (62\%). ${ }^{32}$

A partir de 2009, o mesmo IBOPE passou a divulgar um Índice de Confiança Social, ${ }^{33}$ composto da confiança declarada em várias instituições, dentre elas os sindicatos. Embora as metodologias de 1990 e as mais recentes não sejam comparáveis, a pesquisa revela que, em 2009, num índice que variava de 0 (nenhuma confiança) a 100 (muita confiança), os sindicatos atingiram 46 pontos, ocupando o quarto lugar entre os menores índices, acima apenas dos partidos políticos, do Congresso Nacional e do sistema público de saúde, e bem distante do Corpo de Bombeiros, instituição mais confiável, com 88 pontos. $^{34} \mathrm{Em}$ 2013, última data

${ }^{32}$ Dados tabulados para este estudo a partir do banco original arquivado no CESOP/UNICAMP.

${ }_{33}$ Disponível em http://www.ibope.com.br/pt-br/noticias/ Paginas/Cai-a-confianca-dos-brasileiros-nas-instituicoes-. aspx (acessado em junho de 2015).

${ }^{34} \mathrm{O}$ índice é composto da média de quatro possibilidades de resposta, padronizadas para variar entre 0 e 100. Quem diz ter muita confiança na instituição recebe o valor 100, alguma confiança 66, quase nenhuma confiança 33, e nenhuma confiança 0 (zero). 
disponível enquanto escrevo, aquele índice havia caído para 37 pontos. A queda, é bom marcar, foi generalizada, e, mesmo o Corpo de Bombeiros, perdeu 11 pontos, caindo para 77 em cinco anos. O clima pós junho de 2013, quando o último levantamento foi realizado, era mesmo de descrença geral nas instituições, e os sindicatos não ficaram ilesos.

Não se deve esquecer a crise política envolvendo o PT e vários de seus líderes com origem no movimento sindical, que também é parte ou ajuda a construir a crise de confiança. Desde o escândalo do "mensalão", em 2005-2006, o partido vem sendo objeto de investigação policial e condenações na justiça, o que tem revelado os meandros de uma forma, para dizer o mínimo, pouco ortodoxa de financiamento das trajetórias políticas de seus membros e dos partidos aliados. Ainda que sistemas corruptos de financiamento da política sejam uma preocupação constante das democracias (Zovatto, 2005), e no Brasil sejam um segredo de polichinelo (Power e Taylor, 2013), o fato é que o PT, e não outros partidos, foi capturado na rede de seus opositores, e todo o projeto político, exitoso nos anos Lula a ponto de este ter deixado o governo com mais de $80 \%$ de aprovação e eleger como sucessora uma pessoa desconhecida dos brasileiros, perdeu o capital acumulado a duras penas. Os escândalos de corrupção criminalizaram a disputa política, que tem neste o principal tema da agenda pública, e isso será assim por muito tempo, porque foi este o canal encontrado por opositores para desalojar o PT do poder federal. A crise atual do PT é, também, a crise das correntes hegemônicas do sindicalismo (CUT e CTB, mas, também, a Força Sindical no segundo mandato de Lula), ${ }^{35}$ levadas de roldão pela onda de criminalização das lideranças e da prática política do PT.

${ }^{35}$ Uma velha raposa política costumava dizer que a política é como nuvem, você olha ela está de um jeito, olha de novo e ela já mudou (atribuído ao político mineiro Magalhães Pinto). Por isso utilizo "derrota atual" do PT.

\section{CONCLUSÃO}

O projeto político que uniu CUT e PT nos anos 1980 cumpriu a utopia varguista da gestão do capitalismo pelo trabalho organizado, cinquenta anos depois de formulada. Os trabalhadores "são o governo". É claro que, num presidencialismo de coalizão, ${ }^{36}$ estar no comando do governo não confere poderes irrestritos. Muito da agenda daquele projeto político não pôde se materializar em políticas públicas, nem mesmo timidamente. ${ }^{37}$ Parte dos dilemas atuais do sindicalismo decorre disso.

Em primeiro lugar, é difícil para os membros de uma coalizão vitoriosa de forças políticas e sociais voltar-se contra os mecanismos que permitiram seu acesso ao poder de Estado. Não parece lógico esperar que lideranças sindicais, que tiveram na estrutura herdada de Vargas, e apenas parcialmente reformada em 1988, seu berço e terreno onde vicejar, trabalhem para mudar a legislação. Abrir a discussão sobre isso significaria inaugurar um ambiente de incerteza quanto ao futuro do ordenamento sindical e dos direitos do trabalho, que essas lideranças estiveram pouco dispostas a avalizar, mesmo no ambiente altamente favorável dos dois primeiros governos do PT, marcados por crescimento econômico, geração de empregos e melhoria na renda das famílias. Numa situação de crise econômica (que tende a fragilizar a posição dos trabalhadores no mercado de trabalho, por causa do aumento do desemprego ${ }^{38}$ ), e também política, na qual

${ }^{36}$ O conceito de "presidencialismo de coalizão" foi cunhado por Sergio Abranches (1988) para caracterizar o regime político brasileiro, definido pelo compartilhamento do poder de Estado entre o Executivo e o Legislativo. Como o presidente eleito dificilmente terá maioria no Congresso, contando apenas com seu próprio partido, a elevada fragmentação partidária exige a coalizão de forças com outros partidos.

${ }^{37}$ É o caso, por exemplo, da reforma sindical, objeto de intensas negociações no Fórum Nacional do Trabalho, sepultado pelo escândalo do "mensalão" em 2005. Ver o artigo de Almeida (2007), um dos poucos que se debruçaram sobre a experiência frustrada do FNT.

${ }^{38} \mathrm{O}$ desemprego no país subiu de 7,1\% em abril de 2014 para $8 \%$ no mesmo mês em 2015, tendo apresentado trajetória ascendente desde dezembro de 2014, segundo o IBGE. A renda média do trabalho tem-se mantido estável em torno de $\mathrm{R} \$ 1.850,00$. 
as forças que hoje dominam o Congresso Nacional têm conseguido aprovar leis que reduzem direitos trabalhistas, como é o caso do PL4330/04, falar em reforma da legislação sindical (por exemplo, para acabar com o imposto sindical) parece ainda mais temerário.

Porém, e em segundo lugar, a manutenção da estrutura sindical, com sua contradição entre liberdade formal e múltiplas e crescentes restrições à autonomia sindical por parte do Ministério do Trabalho, vem criando vetores de oligarquização do movimento. A configuração atual é favorável ao fortalecimento de algumas centrais sindicais e à fragilização dos sindicatos de base, resultante da incapacidade demonstrada pelos sindicatos de atrair novos adeptos.

A comparação com os fundos públicos dos partidos feita mais acima visa, apenas, chamar a atenção para a enorme atratividade das regras atuais que, repito, são um estímulo à sua reprodução. A ação sindical, para ser eficaz, precisa de recursos financeiros, e as regras e leis que se foram acumulando nos últimos anos, às quais o movimento sindical foi se acomodando pragmaticamente, fortaleceram a posição dos que defendem a manutenção do imposto sindical.

Tudo isso ocorre num ambiente de desเด crédito da maioria da população em relação సं às instituições tradicionais de representação Ф் de interesses, agora incluindo os sindicatos. O Brasil pós-junho de 2013 é um país no qual todas as dimensões da vida foram politizadas. 施 Tudo é objeto de questionamento, mobilizaa seios emergentes em estratégias de ação. $\mathrm{O}$ ণ sindicalismo está entre elas. Colhido pela cri-

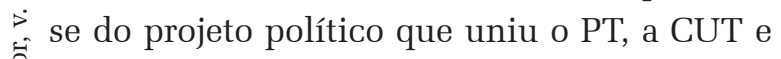
parcela expressiva das outras correntes sindicais, precisaria se reinventar, mas tem escolhiI do se apegar aos mecanismos tradicionais de reprodução, pondo-se na defensiva. Continuará, com isso, lutando por direitos e salários nas negociações coletivas, mas terá perdido a chance de ter papel relevante na renovação do que chamei, aqui, de espírito do tempo, que, parafraseando Karl Manheim (1928), deve ser entendido como a matriz hegemônica de interpretação do estado atual de coisas na ordem social, ou sua enteléquia.

Recebido para publicação em 11 de junho de 2015 Aceito em 05 de agosto de 2015

\section{REFERÊNCIAS}

ABRANCHES, Sergio H. Presidencialismo de coalizão: o dilema institucional brasileiro. Dados, Revista de Ciências Sociais. v. 31, n. 1, p. 5-34. 1988.

ALMEIDA, Gelsom R. O governo Lula, o Fórum Nacional do Trabalho e a reforma sindical. Katálysis. v. 10, n. 1, Florianópolis, Jan./June, disponível em http://www.scielo.br/scielo.php?script =sci_arttext \&pid $=$ S1414-49802007000100007. 2007

BOITO JR., Armando; Marcelino, Paula. O sindicalismo deixou a crise para trás? Um novo ciclo de greves na década de 2000. Caderno CRH, Bahia, v. 23, n. 59, p. 323338. 2010.

CARDOSO, Adalberto M. Sindicatos, trabalhadores e a coqueluche neoliberal. Rio de Janeiro, FGV. 1999.

A década neoliberal e a crise dos sindicatos no Brasil. São Paulo, Boitempo. 2003.

A construção da sociedade do trabalho no Brasil. Uma investigação sobre a persistência secular das desigualdades. Rio de Janeiro, FGV. 2010.

Ensaios de sociologia do mercado de trabalho brasileiro. Rio de Janeiro, FGV. 2013.

. As jornadas de junho e a mercantilização da vida coletiva. Insight Inteligência. Rio de Janeiro, v. 16, n. 62, p. 22-30. 2013b.

Sindicatos no Brasil: passado, presente e futuro. In: CATTANI, Antonio D. (Org.), Trabalho: Horizonte 2021. Porto Alegre, Escritos, p. 121-145. 2014.

; LAGE, Telma. As normas e os fatos. Desenho e efetividade das instituicões de regulação do mercado de trabalho no Brasil. Rio de Janeiro, FGV. 2007.

CASTELS, Manuel. Redes de indignação e esperança. Rio de Janeiro, Zahar. 2013.

CHECCHI, Daniele; VISSER, Jelle. Pattern persistence in European trade union density: a longitudinal analysis 1950-1996. European Sociological Review. v. 21, n.1, p. 1-21. 2005.

CORRÊA, Larissa R. A tessitura dos direitos. Patrões e empregados na Justiça do Trabalho, 1953 a 1964. São Paulo, FAPESP/LTr. 2011.

DIEESE. Taxa de judicialização das negociações coletivas de trabalho no Brasil: 1993-2005. Săo Paulo, DIEESE. Estudos e Pesquisas, n. 21, jun. 2006.

O mercado de trabalho formal brasileiro: resultados da RAIS 2013. Disponível em http://www.dieese.org.br/ notatecnica/2014/notaTec140Rais2013.pdf (consultado em junho de 2015). 2014 
ERICKSON, Kenneth P. Sindicalismo no processo político no Brasil. São Paulo: Brasiliense. 1979.

IBGE. Anuário Estatístico do Brasil 1966. Rio de Janeiro: IBGE, v. 26. 1966.

. Anuário Estatístico do Brasil 1992. Rio de Janeiro: IBGE, v. 52. 1992.

LUCCA, Juan Bautista. Estudio comparado de la identidad partidaria-sindical durante el gobierno de Lula da Silva (Brasil, 2003-2006) y de Néstor Kirchner (Argentina, 20032007). Phd. Dissertation in Social Sciences (Buenos Aires: Facultad Latinoamericana de Ciencias Sociales). 2011.

MANNHEIM, Karl. El problema de las generaciones. Revista Española de Investigaciones Sociológicas, n. 62. (acessível em http://www.reis.cis.es/REIS/PDF/ REIS_062_12.PDF). 1993[1928].

MARICATO, Ermínia et al. Cidades rebeldes. Passe livre e as manifestações que tomaram as ruas do Brasil. São Paulo, Boitempo e Carta Maior. 2013.

MARTINS RODRIGUES, Leôncio. Trabalhadores, sindicatos e industrialização. São Paulo, Brasiliense. 1974.

. Destino do sindicalismo. São Paulo, Edusp. 1999.

MARTINS, Heloísa H. de S. O Estado e a burocratização do sindicato no Brasil. São Paulo, Hucitec (2 ${ }^{\mathrm{a}}$ edição). 1989.

NORONHA, Eduardo G. Greves e estratégias sindicais no Brasil. In: C. A. de Oliveira, J. F. Siqueira Neto; M. A. de Oliveira (Orgs.), O mundo do trabalho: crise e mudança no final do século. Brasília/São Paulo/Campinas, MTb-PNUD/ Cesit/Scritta, p. 323-358. 1994.

Ciclo de greves, transição política e estabilização: Brasil, 1978-2007. Lua Nova, v. 76, p. 119-168. 2009
PIRES, Roberto R. C. (Org.). Efetividade das instituições participativas no Brasil: estratégias de avaliação. Brasília, IPEA. 2011.

POCHMANN, Marcio. O emprego na globalização. São Paulo, Boitempo. 2001.

Nova classe média? O trabalho na base da pirâmide social brasileira. São Paulo, Boitempo. 2012.

POWER, Timothy; TAYLOR, Matthew M. (eds.). Corruption and democracy in Brazil: the struggle for accountability. Notre Dame, University of Notre Dame Press. 2013.

RODRIGUES, Iram J. Para onde foram os sindicatos? Alguns dados para reflexão. Trabalho apresentado no $37^{\circ}$ Encontro Anual da ANPOCS. Águas de Lindoia, setembro. 2013.

SCHMITTER, Philippe C. Interest conflict and political change in Brazil. California, Stanford University Press. 1971.

SILVA, Fernando T. Entre o acordo e o acórdão: a justiça do trabalho paulista na antevéspera do golpe de 64". In: GOMES, Angela de C.; Fernando T. da Silva (eds), A justiça do trabalho e sua história. São Paulo: Editora Unicamp. 2013.

SILVA, Sayonara Grillo C. L. Relações coletivas de trabalho. Configurações institucionais no Brasil contemporâneo. São Paulo: LTr. 2008.

VARGAS, Getúlio. O governo trabalhista do Brasil. Rio de Janeiro: José Olympio, v. 4. 1969.

ZOVATTO, Daniel. Financiamento dos partidos e campanhas eleitorais na América Latina: uma análise comparada. Opinião Pública, Campinas, v. 11, n. 2, p. 287336. 2005 . 


\section{THE EXTENSION OF THE CRISIS IN BRAZILIAN UNIONISM}

\section{Adalberto Cardoso}

The article inquires on the alleged crisis of the Brazilian trade unionism in the last decade. Analyzes some central dimensions of the union dynamics in the country (number of trade unions, membership in central federations, union density, volume of strikes, collective bargaining and others), and shows that in spite of the sharp drop in union density, union actions have proven effective in collective bargaining. The picture of crisis is linked to the overall political environment in which the political project of the movement's hegemonic portion (the CUT and allies) and its parties (the PT and its allies) are today under fire from the forces that oppose them.

KEYwORDs: Trade unionism. Economic crisis. Political crisis. Collective bargaining. Strikes

\section{LES DIMENSIONS DE LA CRISE DU SYNDICALISME BRESILIEN}

\section{Adalberto Cardoso}

Cet article présente une enquête faite sur la crise généralisée des dix dernières années du syndicalisme brésilien. Il analyse quelques dimensions clés de l'organisation syndicale du pays (nombre de syndicats, adhésion à des fédérations syndicales, taux d'adhésion syndicale, quantité de grèves, les négociations collectives et autres) et démontre que malgré une baisse considérable du taux d'adhésion, l'action syndicale s'est montrée efficiente dans les négociations collectives. L'image de la crise est associée à l'ambiance politique générale dans laquelle le projet politique de la partie hégémonique du mouvement (la CUT et ses alliés) et ses partis (o PT et ses alliés) sont aujourd'hui dans le collimateur des forces qui s'opposent à eux.

Mots-clés: Syndicalisme. Crise économique. Crise politique. Négociation collective. Grèves. nas áreas de sociologia do trabalho, sociologia urbana, sociologia da juventude, desigualdades sociais e teoria social. Dentre seus livros recentes destacam-se Brazil emerging: inequality and emancipation (New York: Routledge, 2014), organizado com Jan Nederveen Pieterse; Ensaios de sociologia do mercado de trabalho brasileiro, (Rio de Janeiro, FGV, 2013); A construção da sociedade do trabalho no Brasil: uma investigação sobre a persistência secular das desigualdades (Rio de Janeiro, FGV, 2010). 